This item was submitted to Loughborough's Research Repository by the author.

Items in Figshare are protected by copyright, with all rights reserved, unless otherwise indicated.

\title{
Boundary conditions for elastohydrodynamics of circular point contacts
}

PLEASE CITE THE PUBLISHED VERSION

http://dx.doi.org/10.1007/s11249-013-0249-0

PUBLISHER

(c) Springer Science + Business Media

VERSION

AM (Accepted Manuscript)

LICENCE

CC BY-NC-ND 4.0

REPOSITORY RECORD

Mohammadpour, Mahdi, P.M. Johns-Rahnejat, Homer Rahnejat, and Ramsey Gohar. 2013. "Boundary Conditions for Elastohydrodynamics of Circular Point Contacts". Loughborough University. https://hdl.handle.net/2134/14289. 


\title{
Boundary conditions for elastohydrodynamics of circular point contacts
}

\author{
M. Mohammadpour ${ }^{1}$, P.M. Johns-Rahnejat*, \\ H. Rahnejat ${ }^{1}$ and R. Gohar ${ }^{2}$ \\ ${ }^{1}$ Wolfson School of Mechanical \& Manufacturing Engineering, \\ Loughborough University, Loughborough, UK \\ ${ }^{2}$ Department of Mechanical Engineering, Imperial College London, UK \\ formerly at Imperial College, London, UK
}

\begin{abstract}
:
The paper presents the solution of an elastohydrodynamic point contact condition using inlet and outlet lubricant entrainment with partial counter-flow. The inlet and outlet boundaries are determined using potential flow analysis for the pure rolling of contiguous surfaces. This shows that Swift-Stieber boundary conditions best conform to the observed partial counter-flow at the inlet conjunction, satisfying the compatibility condition. For the outlet region the same is true when Prandtl-Hopkins boundary conditions are employed. Using these boundary conditions, the predictions conform closely to the measured pressure distribution using a deposited pressure sensitive micro-transducer in a ball-to-flat race contact. Furthermore, the predicted conjunctional shape closely conforms to the often observed characteristic key-hole conjunction observed through optical interferometry. The combined numericalexperimental analysis with realistic boundary conditions described here has not hitherto been reported in literature.
\end{abstract}

Keywords: Elastohydrodynamics, inlet and outlet boundary conditions, lubricant flow, contact pressure measurement, micro-transducer 


\section{Nomenclature:}

$a \quad$ : Contact semi-major half-width

$b \quad:$ Contact semi-minor half-width

F $\quad$ : Applied load

$H \quad$ : Dimensionless film thickness $\frac{h R_{x Z}}{b^{2}}$

$h \quad$ : Film thickness

$h_{0} \quad$ : Central film thickness

$h_{0 l} \quad:$ Local central film thickness

$k \quad:$ Speed ratio

$K \quad$ : Ellipticity ratio

$P \quad$ : Dimensionless pressure $p / P_{\max }$

$P_{\max }:$ Maximum Hertzian pressure

$p \quad:$ Pressure

$R_{z x} \quad$ : Equivalent radius of contact along the direction of minor axis of elliptical footprint

$R_{z y} \quad$ : Equivalent radius of contact along the direction of major axis of elliptical footprint

$r \quad$ : Local radius of curvature

$S \quad$ : Contact profile of the equivalent solid

$U \quad$ : Speed of entraining motion $\frac{U_{1}+U_{2}}{2}$

W : Calculated load

$x \quad$ : Direction/distance of entraining motion

$X \quad$ : Dimensionless direction/distance of entraining motion $x / b$

$y \quad$ : Direction/distance of side leakage

$Y \quad$ : Dimensionless direction/distance of side leakage $y / b$

\section{Greek symbols}

$\alpha \quad$ : Lubricant pressure-viscosity coefficient

$\delta \quad:$ Deflection 
$\varepsilon_{w} \quad:$ Load error tolerance

$\varepsilon_{p} \quad:$ Pressure error tolerance

$\eta_{0} \quad$ : Inlet viscosity

$\eta \quad$ : Viscosity

$\bar{\eta} \quad$ : Dimensionless viscosity $\left(\eta / \eta_{0}\right)$

$\theta \quad$ : Position angle

$\lambda \quad$ : Stribeck oil film parameter

$v \quad$ : Transformed dimensionless direction of side leakage

$\rho_{0} \quad$ : Inlet density

$\rho \quad$ : Density

$\bar{\rho} \quad$ : Dimensionless density $\left(\rho / \rho_{0}\right)$

$\varsigma \quad$ : Damping factor for load balance

$\sigma \quad$ : Composite surface roughness

$\tau \quad:$ Shear stress

$\chi \quad$ : Transformed direction of entraining motion

$\Omega \quad$ : Under-relaxation factor

\section{Subscripts:}

$$
\begin{array}{ll}
c & : \text { Current analysis } \\
e & : \text { Exit } \\
f & : \text { Fully flooded } \\
i & : \text { Inlet }
\end{array}
$$




\section{Introduction}

The concentrated contact of highly stressed load bearing conjunctions such as ball and rolling element bearings or cam-follower pairs and gears is subject to an elastohydrodynamic regime of lubrication. Understanding of the elastohydrodynamic phenomenon has evolved significantly since the pioneering paper by Grubin [1], based on the work of Ertel [2]. Ertel and Grubin postulated the piezo-viscous action of the lubricant at the inlet nib to a contact obeying localised classical Hertzian deformation. A parallel film conjunction was assumed with the contact pressure profile closely following the elliptical Hertzian pressure distribution for an infinite line contact. Dowson and Higginson [3] provided the first numerical solution for this case and noted a secondary pressure peak at the exit constriction. Later, Archard and Kirk [4], Archard and Cowking [5] and Cameron and Gohar [6] extended the numerical solution to the case of a point contact under pure rolling motion. Validity of the numerical predictions was confirmed by optical interferometric studies, pioneered by Gohar and Cameron [7]

However, many conjunctions such as those of balls in their raceway grooves are subject to combined rolling and sliding motion and have an elliptical footprint owing to the slight conformance of the mating solids. Solutions include those by Chittenden et al [8] and Jalali-Vahid et al [9,10]. The latter showed agreement between their numerical predictions and the optical interferometric studies of Thorp and Gohar [11] for elliptical point contacts of ball-raceway grooves and angled entraining flow of lubricant into the contact conjunction. The initial line contact analysis by Dowson and Higginson [3] ignored side leakage of the lubricant in finite line contacts such as in rollers to raceway contacts in rolling element bearings. Later works by Mostofi and Gohar [12] and Kushwaha et al [13] included the two dimensional solution of a rollerraceway contact, having a footprint resembling a dog-bone or a dumbbell [14]. These contact footprint shapes were reported earlier by Hartnett and Kannel [15], and Johns and Gohar [16] among others. Mostofi and Gohar [12] and Kushwaha et al [13] showed good agreement between elastohydrodynamic finite line contact predictions and the interferometric studies of Wymer and Cameron [17].

Elastohydrodynamic pressure distribution was shown to follow the Hertzian pressure profile except for the inlet hydrodynamic trail and a secondary pressure peak near the exit constriction. The minimum film thickness occured in the close vicinity of this pressure peak. For point contact geometry, interferograms of the contact revealed a "horse-shoe" shape constriction at the exit as early as the 1960s [7]. This has since been confirmed by others, such as Foord et al [18] and Thorp and Gohar [11].

The measurement of pressure in elastohydrodynamic conjunctions received a boost through the deposition of thin films of pressure sensitive bulk manganin by Bridgeman [19] who used it for high-pressure vessel applications. Kannel et al [20] 
made the first miniature manganin transducer in the form of a thin strip to measure elastohydrodynamic line contact pressures in the rolling contact of cylinders. Kannel [21] made comparisons between numerically predicted pressure profiles and those measured by a manganin transducer for line contact conditions. Although good agreement was obtained, the magnitude of the secondary pressure peak was found to be much smaller than that predicted numerically. The reason for this anomaly was the width of the device which affected the measurement resolution. Other investigators such as Hamilton and Moore [22], Bartz and Ehlert [23] and Safa et al [24] further miniaturised the transducer to improve its resolving power. However, the theoretical predictions still showed much larger pressure spikes than those measured under the same conditions. The prediction of the magnitude of the pressure spike is was important because the spike induced a sub-surface stress field of its own, which was superimposed upon that predicted for the equivalent Hertzian point [25] and line [26] contact conditions.

The deviation between predictions and measurements resulted from miniaturised transducer width (resolution), and interval width in the discretised numerical procedure. Al-Samieh and Rahnejat [27] showed that the monitored pressure spike could be predicted accurately once these issues were adequately addressed. Their predictions agreed well with the measured pressure distributions for a ball bearing falling freely upon an oily glass plate upon which Safa and Gohar [28] had fabricated a manganin micro-transducer. Therefore, numerical elastohydrodynamic solvers could now predict elastohydrodynamic conjunctions fairly satisfactorily.

A miniature manganin pressure transducer (described later) was sputter-etched through a laser cut molybdenum foil onto the glass race of a three ball interferometric rig by Johns-Rahnejat [29] to study pressure distribution under circular point contact conditions. Fine positioning of the active element of the transducer in the path of the traversing balls enabled the acquisition of cross-sectional elastohydrodynamic pressure profiles in the direction of entraining motion. Assembling these pressure traces yielded a three dimensional contact pressure distribution in an isobaric form (Johns-Rahnejat and Gohar [30]). Miniaturisation of the device enabled good resolution of in the region of the secondary pressure peak (pip) just prior to the exit boundary. The authors used the result of partial counter flow analysis expounded by Tipei [31] to establish the inlet and outlet flow boundaries. The outlet boundary was compared with the interferograms of the oil film contours under identical load and kinematic conditions and revealed remarkable conformance of experimentally obtained wake flow boundaries with those of Tipei [31]. An expected conclusion of this work was that bearings usually run under starved conditions where much of the flow, entrained from an inlet meniscus, is diverted onto the shoulders of the contact through side leakage. Also, the inlet meniscus was found to curve inwards in accord with observations in practice and underpinned by the characteristic Young-Laplace equation. 
There could still be significant deviation between numerical predictions and the actual conditions in practice on account of the assumed boundary conditions. Numerical analyses often assume fully flooded inlet boundaries and exit constrictions based upon Swift-Stieber film rupture conditions beyond the Hertzian domain. More representative analyses have included inlet boundaries based upon demarcation lines for just fully flooded conditions, determined numerically (Hamrock and Dowson [32]) or experimentally using interferometric studies (Wedeven et al [33]). However, these were not based on any quantitative free surface lubricant flow analysis such as that underlying Prandtl-Hopkins zero reverse flow boundaries.

It is essential to determine the correct inlet and outlet boundary conditions as these affect the resulting pressure distribution and lubricant film thickness. This constitutes the main focus of the current study, which includes the determination of the inlet meniscus and outlet wake flow boundaries based on Tipei's counter-flow analysis. It is also important to gauge the validity of the determined boundary conditions, which result in the observed characteristic "key hole" shape contact. This is achieved by comparison of predictions with the interferogram of lubricant film contour as well as the isobaric pressure plot obtained through the use of a miniature manganin pressure transducer, previously reported in [30] and described in more detail in this paper. The results show good agreement between measurements and predictions, indicating the formation of complex inlet and outlet boundaries. The inlet to the conjunction follows the Prandtl-Hopkins zero reverse flow boundary, with the outlet boundary forming along the characteristic wake flow beyond the contact shoulders. The wake flow extends inwards to the exit constriction, where predictions confirm the Swift-Stieber boundary beyond the high pressure Hertzian contact region.

The results also show that the inlet meniscus is actually formed inside the starvation demarcation boundary found through usual numerical analysis or deduced from optical interferometric studies of partially lubricated conjunctions. This finding indicates that elastohydrodynamic conjunctions are often starved even under nominally pure rolling conditions as has often been surmised but not fundamentally determined. This finding has been a repercussion of the analysis with the use of correct boundary conditions, rather than its primary objective.

\section{Experimental set up and the thin film pressure transducer}

Figure 1(a) shows a three ball machine. It comprises a flat driven lower race made of EN31 steel ( $1 \% \mathrm{C}, 1.4 \% \mathrm{Cr})$, lapped to a finish of $0.1 \mu \mathrm{m}$ and a toughened optical crown glass stationary top race of $0.08 \mu \mathrm{m} \mathrm{Ra}$, intervened by a driven steel cage, containing three equi-pitched (at $120^{\circ}$ spacing) $25.4 \mathrm{~mm}$ diameter ball bearings of sphericity of $0.1 \mu \mathrm{m}$ and surface roughness of $0.05 \mu \mathrm{m}$ Ra. The cage pockets are lined with PTFE to prevent the balls from being scratched when they are centrifugally loaded against the cage pocket rims at high speed. Figure 1(b) shows the velocity distribution. The glass race is fitted into a collar and loaded upon the rotating balls by a lever loading arrangement and an air bearing (figure 1(a)). Three small 
circumferential plastic screws, equally spaced around the rim of the collar, enable fractional horizontal movement of the glass race. This enables precision positioning of the transducer's active element with respect to the track of the balls. Therefore, cross-sectional pressure distributions under given load-speed combinations can be acquired through a series of experiments.

A miniature manganin pressure transducer is fabricated onto the stationary glass race by RF sputtering at a frequency of $13.56 \mathrm{MHz}$ in a vacuum chamber at $10^{-7}$ Torr. The dimensions of the transducer are shown in figure 2. The active element is a rectangular strip of fine width $(10 \mu \mathrm{m})$, which is suitable to resolve the elastohydrodynamic pressure spike at the exit constriction of the conjunction of any of the balls traversing the transducer.

Manganin $(84 \% \mathrm{Cu}, 12 \% \mathrm{Mn}$ and $4 \% \mathrm{Ni})$ is a piezo-resistive compound with very low temperature sensitivity $\left(\approx 10^{-4} /{ }^{\circ} \mathrm{C}\right)$ and surface stress sensitivity. Its pressure coefficient is linear over a very wide range of pressures. For the thin film transducer, the pressure coefficient is $1.5 \times 10^{-2} \mathrm{~m}^{2} / \mathrm{GN}$. The manganin pressure transducer is unsuitable for rapid transient pressure variations and unsuitable for use with electrically conducting surfaces $[34,35]$. Therefore, it is deposited on a layer of refractory material such as alumina. Depletion of lubricant film can also cause a short circuit when the transducer directly contacts the ball.

At a given load the ball cage and the race are driven in accord with figure 1(b) in order to achieve pure rolling motion of the ball-lower race contact and thus attain, as far as possible, a circular point contact condition. The true speeds of the lower race and cage are measured using photo-sensors to detect the difference in reflected light from black and white stripes fabricated on their rims. 


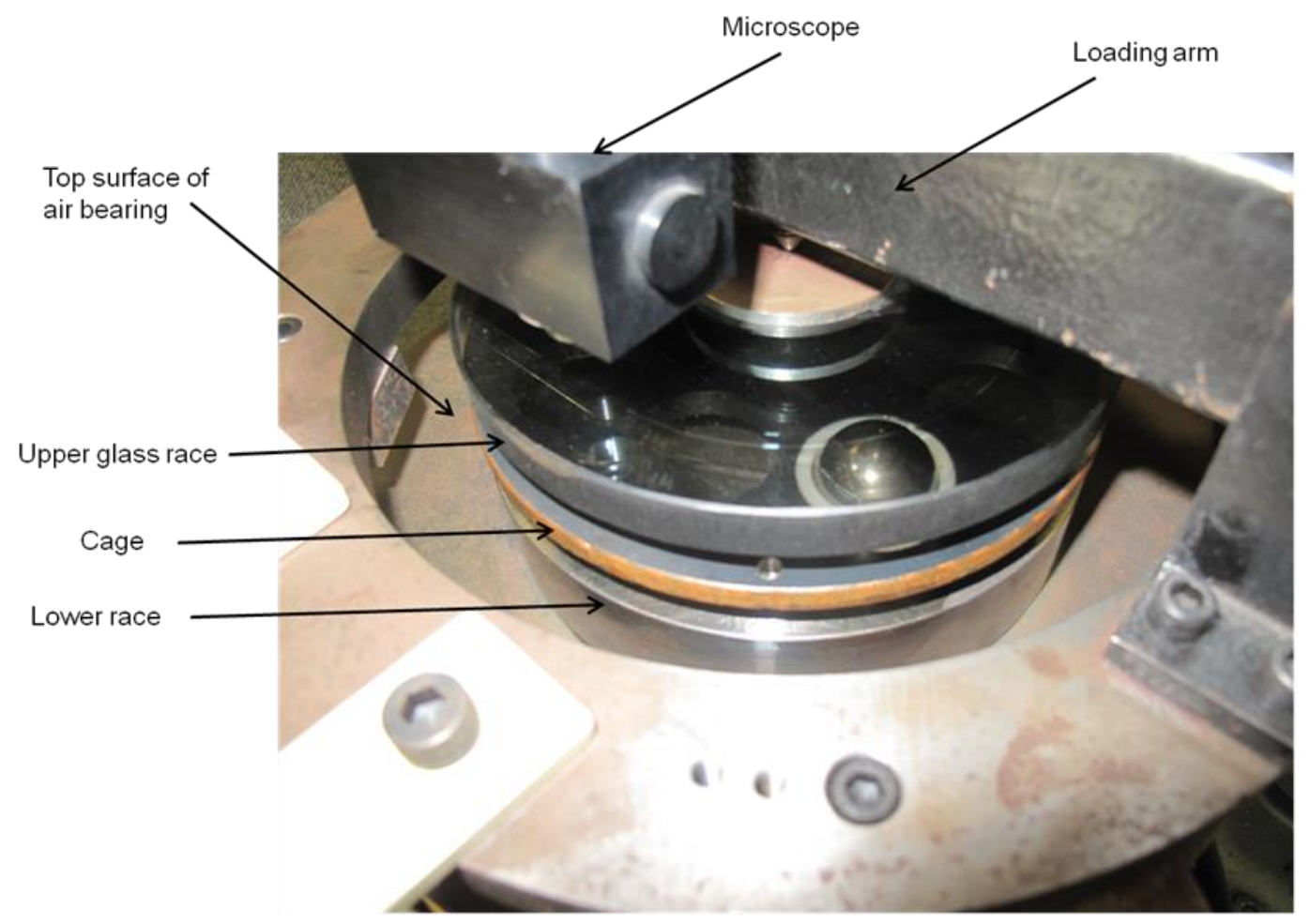

(a)- The rig

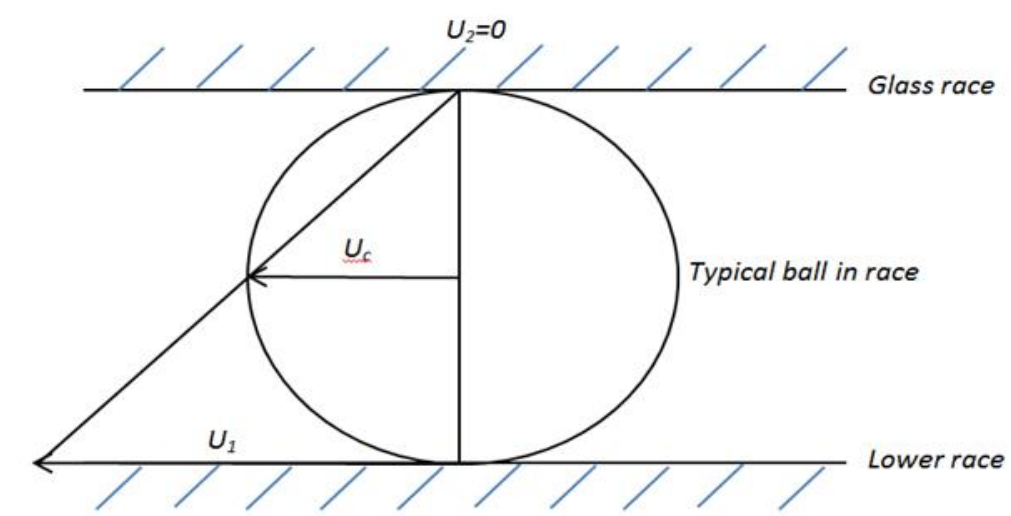

(b)- Contact kinematics

Figure 1: The Experimental set up 

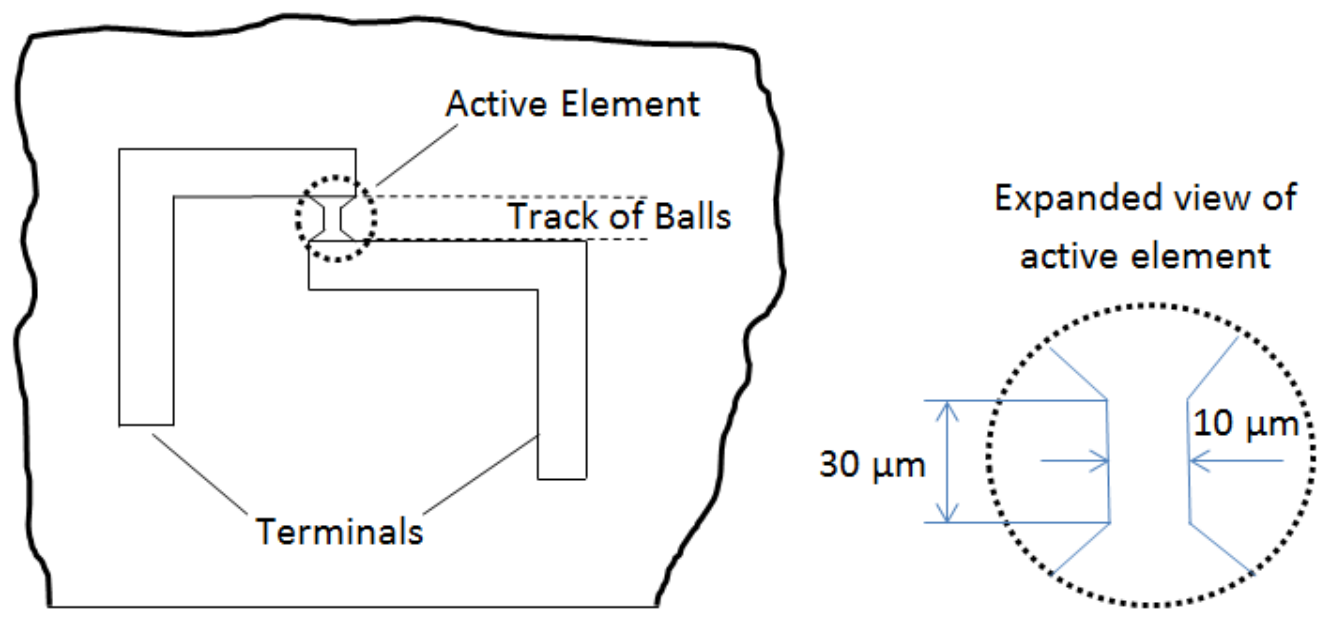

Top view

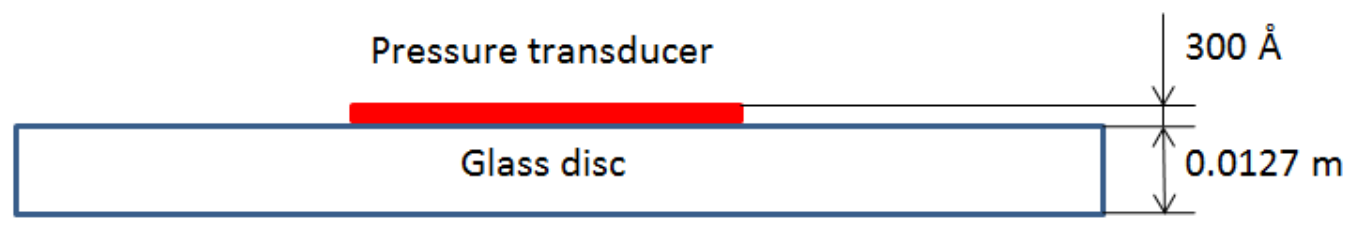

Side view

Figure 2: The manganin pressure micro-transducer

\section{Measurement of elastohydrodynamic pressures}

Figure 3(a) shows a series of pressure traces obtained from various point contact cross-sections in the direction of entraining motion, $X=\frac{x}{b}$, where $a$ is the radius of the Hertzian circle (rolling direction of a ball traversing the transducer's active element). These pressure traces are obtained at various contact cross-sections; $Y=$ $\frac{y}{a}$. Then, the outlet to these pressure traces is set at the exit wake flow boundary calculated by Tipei [31] (figure 3(b)). Therefore, the locus of the inlet meniscus is obtained as the zero pressure isobar in figure 4. 


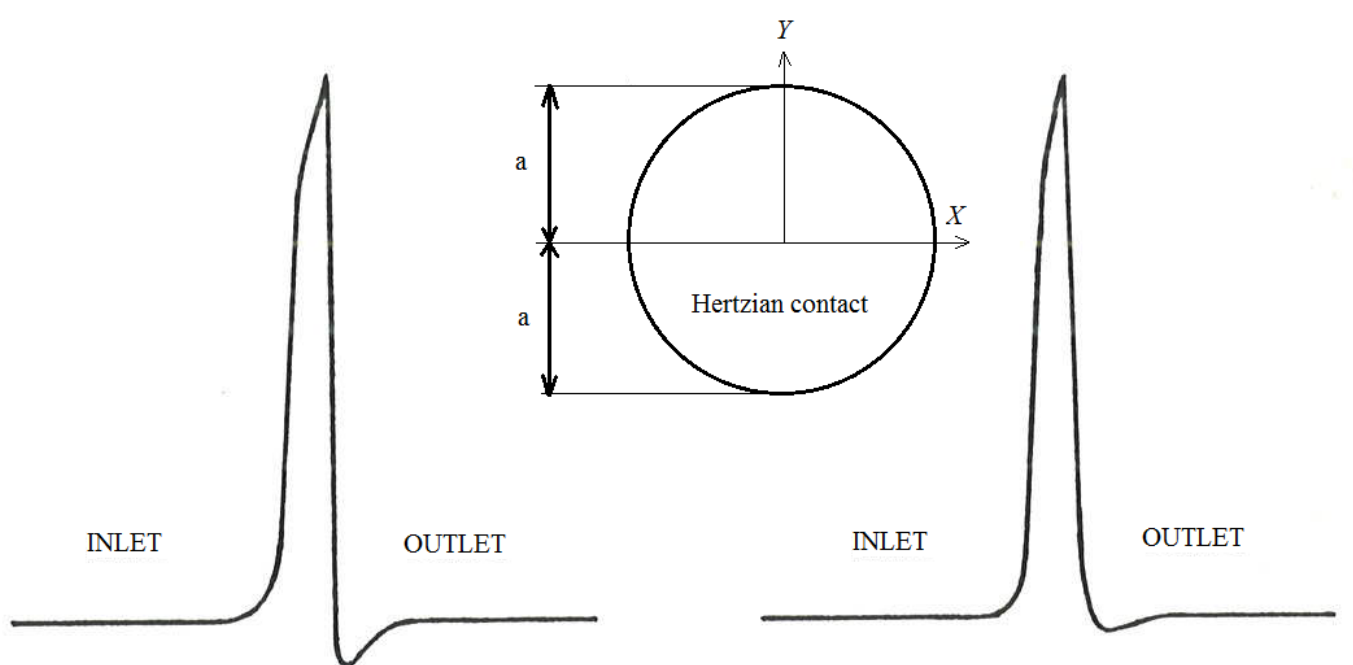

(i) $0.27 \mathrm{a}$

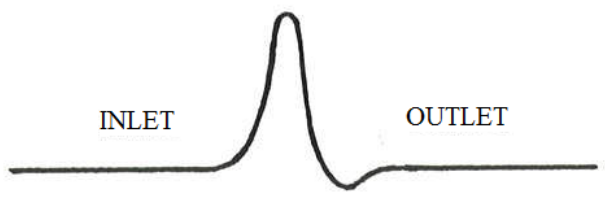

(iii) $1.13 \mathrm{a}$ (ii) $0.85 \mathrm{a}$

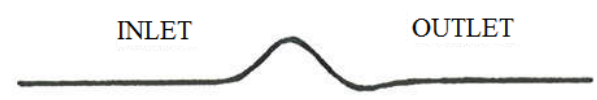

(iv) $1.94 \mathrm{a}$

(a)- Acquired pressure traces at various contact cross-sections

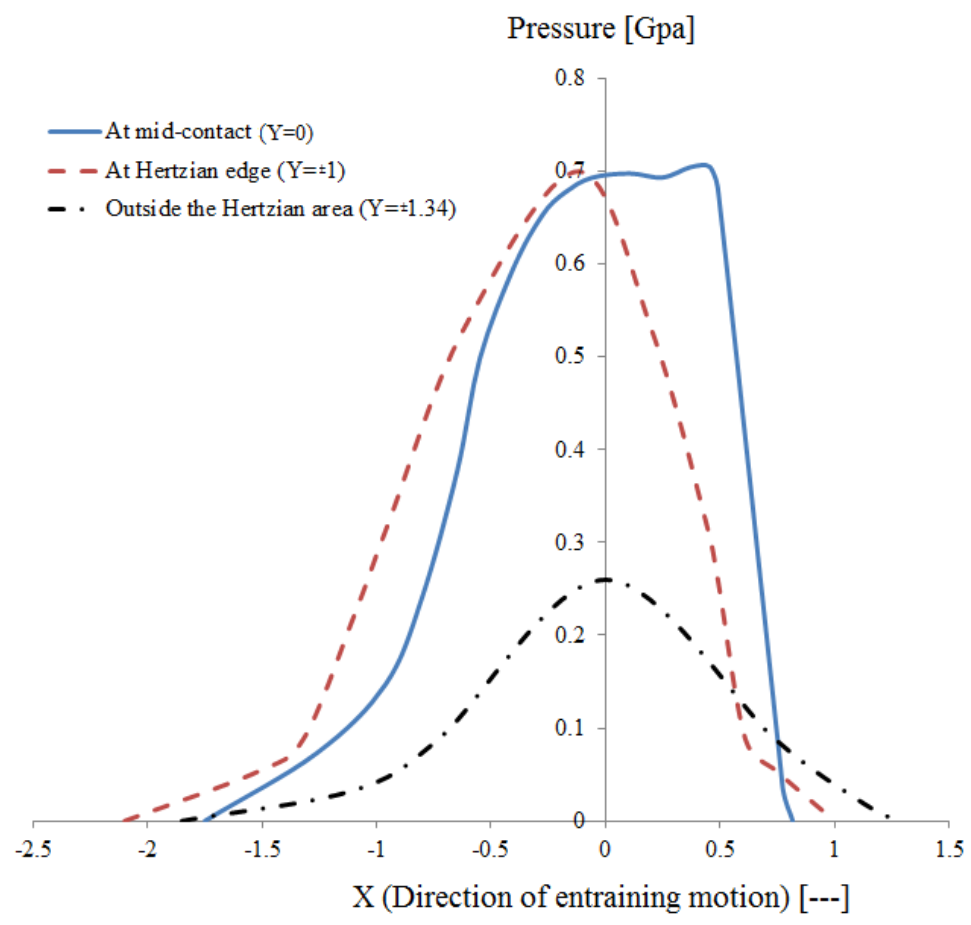

(b)- Calibrated and positioned pressure traces with respect to the outlet wake boundary 
Figure 3: Cross-sectional measured pressure distributions

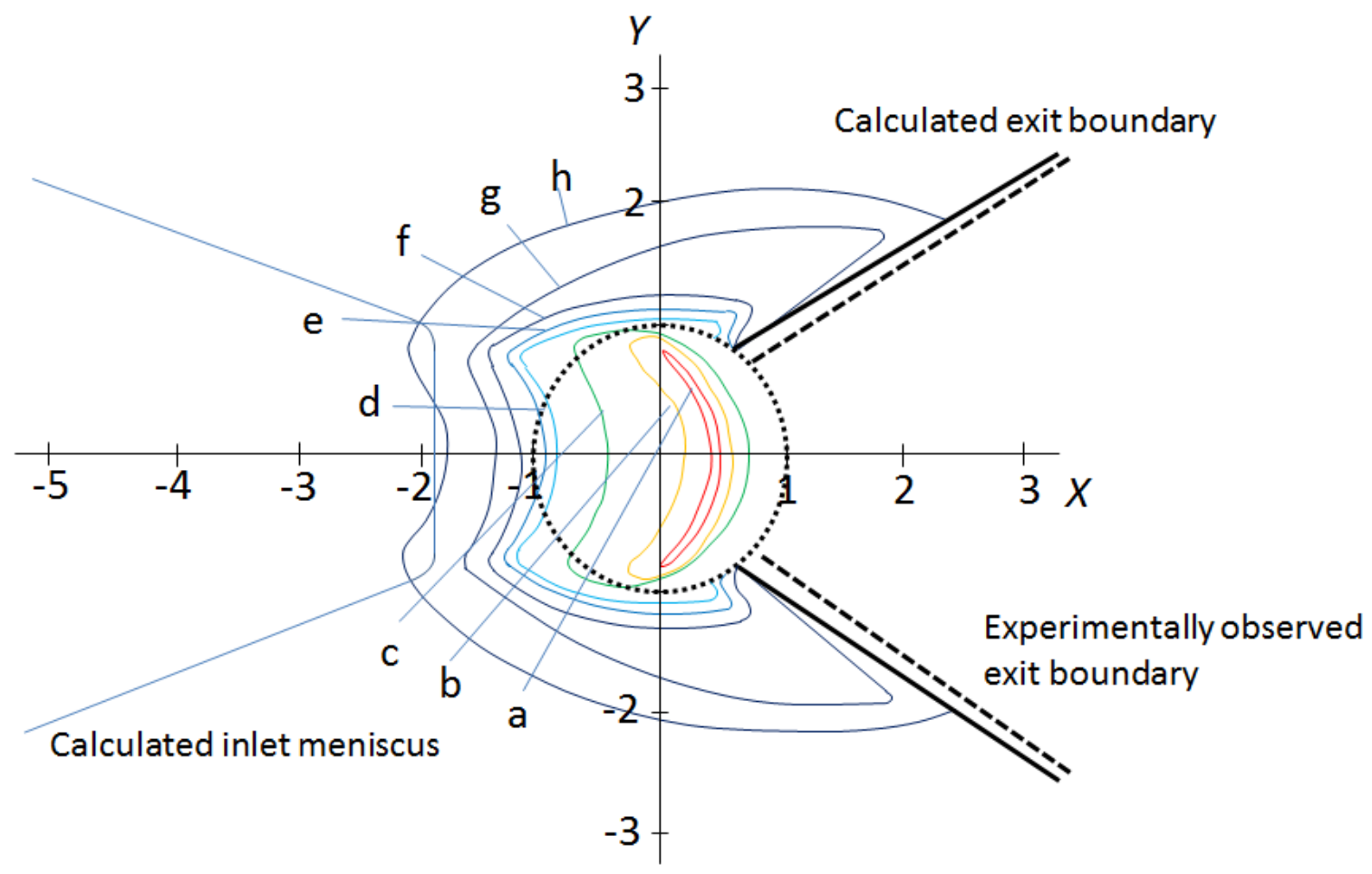

Figure 4: The constructed measured isobaric pressure plot

Key: Pressures in GPa: $a=0.71, b=0.7, c=0.53, d=0.32, e=0.26, f=0.088, g=0.053, h=0$

This inlet boundary is therefore obtained by reconstruction of the zero pressure isobar of a series of experimentally obtained pressure trace cross-sections. The inlet meniscus is quite different from the inlet boundaries usually assumed in numerical analyses as noted by Tipei [31].

\section{Determination of inlet and outlet boundaries}

The main problem in any numerical analysis of the elastohydrodynamic lubrication $(E H L)$ problem is the determination of the true computational domain boundaries. This case has been investigated by Wedeven et al [33]. The balance between the rate at which oil is entrained into the contact zone and that at which it leaks out of the contact edges determines the inlet boundary position according to Pemberton et al [36]. However, the computation domain is generally simplified to a rectangular area $[37,38]$, particularly with the usually assumed fully flooded inlet. It is also quite difficult to consider a computation domain of the form as that represented by, for example, the zero pressure isobar in figure 4. 
It is, nevertheless, important to determine the appropriate inlet boundary condition as this affects the entrainment flow into the contact and hence the film thickness. Tipei [31] investigated the inlet and outlet boundaries of the domain in hydrodynamic contacts (figure 5). He found that in the inlet zone (inset to the figure), there are swirl flows, where some reverse flow (counter flow) occurs at the inlet as is also noted in the experimental observations [39]. This means that only a fraction of inlet lubricant flow is admitted into the contact domain. Considering the potential flows in the inlet region $\left(Q_{1}, Q_{2}, Q_{3}\right)$ in figure $5(\mathrm{~b})$, the compatibility condition yields [31]:

$$
\begin{aligned}
& \cot ^{2} \pi\left[\frac{1}{2}-\frac{1-k}{f(k)}\right]-\cot ^{2} \pi \sqrt{\left[\frac{1}{2}-\frac{1-k}{f(k)}\right]^{2}-\frac{2 k}{f(k)}}=\cot \pi\left\{\frac{1}{2}-\frac{1-k}{f(k)}-\sqrt{\left[\frac{1}{2}-\frac{1-k}{f(k)}\right]^{2}-\frac{2 k}{f(k)}}\right\} \times \\
& \cot \pi\left\{\frac{1}{2}-\frac{1-k}{f(k)}+\sqrt{\left[\frac{1}{2}-\frac{1-k}{f(k)}\right]^{2}-\frac{2 k}{f(k)}}\right\}
\end{aligned}
$$

where:

$k=\frac{U_{1}}{U_{2}}$

and $f(k)$ depends on the pressure gradient. At the inlet point $A$ in figure $5, \frac{d p}{d \theta_{i}} \propto k$, thus for the aforementioned inlet flow rates $\left(Q_{1}, Q_{2}, Q_{3}\right)$ :

$2(1+\sqrt{k})^{2} \leq f(k) \leq 6(1+\sqrt{k})$

The values of $f(k)$ for usually encountered cases of $k$ are listed in table 1 . 


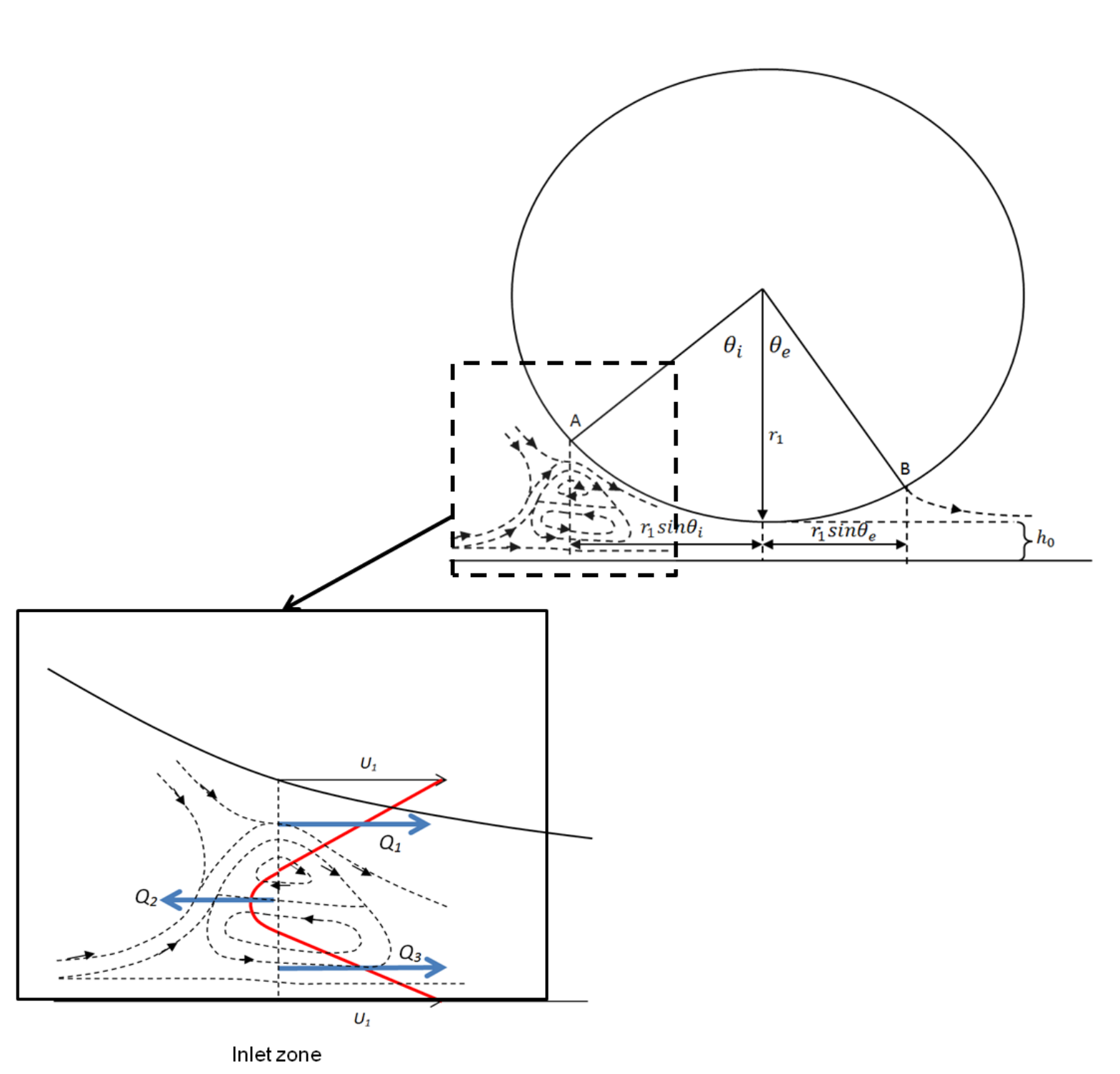

Figure 5: Flow through contact carried by the solid surfaces

Table.1: calculated values for $\mathrm{f}$

\begin{tabular}{|c|c|}
\hline$k$ & $f(k)$ \\
\hline 0 & 4 \\
\hline 0.5 & 7.8 \\
\hline 1 & $32 / 2$ \\
\hline
\end{tabular}

Tipei [31] used the Swift-Stieber condition at the inlet, since the Prandtl-Hopkins boundary conditions do not allow the observed swirl flow there, thus:

$$
\cos \theta_{i}=-\left[1-\frac{h_{0}}{r}\left(\cosh \vartheta_{i}-1\right)\right]
$$


where:

$\frac{\cosh \vartheta_{i}}{\cosh \vartheta_{e}}=\frac{1-\frac{1}{3}\left(1+\frac{2 \sqrt{k}}{1+k}\right)}{1-\frac{f(k)}{6(1+k)}}$

$\left[1-\frac{1}{3}\left(1+\frac{2 \sqrt{k}}{1+k}\right)\right] \tanh \vartheta_{e}-\left[1+\frac{f(k)}{6(1+k)}\right] \tanh \vartheta_{i}-\left[1-\frac{f(k)}{6(1+k)}\right] \cosh \vartheta_{i}\left[\arcsin \left(\tanh \vartheta_{e}\right)-\right.$ $\left.\arcsin \left(\tanh \vartheta_{i}\right)\right]=0$

This inlet boundary is shown in figure 4 as the calculated inlet meniscus, which closely follows the experimentally obtained zero pressure isobar in the central region of the contact domain.

The experimental observations suggest that the separation point at the outlet (film rupture point) is better described by the generation of negative velocities in the lubricant film. Thus, Tipei [31] argued that Prandtl-Hopkins conditions are best suited for the outlet boundary:

$\cos \theta_{e}=-\left[1-\frac{h_{0 l}}{r}\left(\cosh \vartheta_{e}-1\right)\right]$

Where:

$\frac{\cosh \vartheta_{e}}{\cosh \vartheta_{i}}=1-\frac{f(k)}{6(1+k)}$

$\tanh \vartheta_{e}-\left[1+\frac{f(k)}{6(1+k)}\right] \tanh \vartheta_{i}-$

$\left[1-\frac{f(k)}{6(1+k)}\right] \cosh \vartheta_{i}\left[\arcsin \left(\tanh \vartheta_{e}\right)-\arcsin \left(\tanh \vartheta_{i}\right)\right]=0$

The resulting outlet boundary is the one used to lay the exit constrictions of the pressure traces of figure 3 on, hence forming the isobaric pressure plot of figure 4 . This calculated exit boundary closely follows the experimentally obtained wake flow boundary under the same condition in the interferogram of figure 6 .

Therefore, for numerical predictions, the choice of the above calculated inlet and outlet conditions would be appropriate to closely replicate the experimental measurements. The inlet and outlet boundaries are assumed as shown in the figure. It comprises the rear of the Hertzian region and the outlet wake boundary line. 


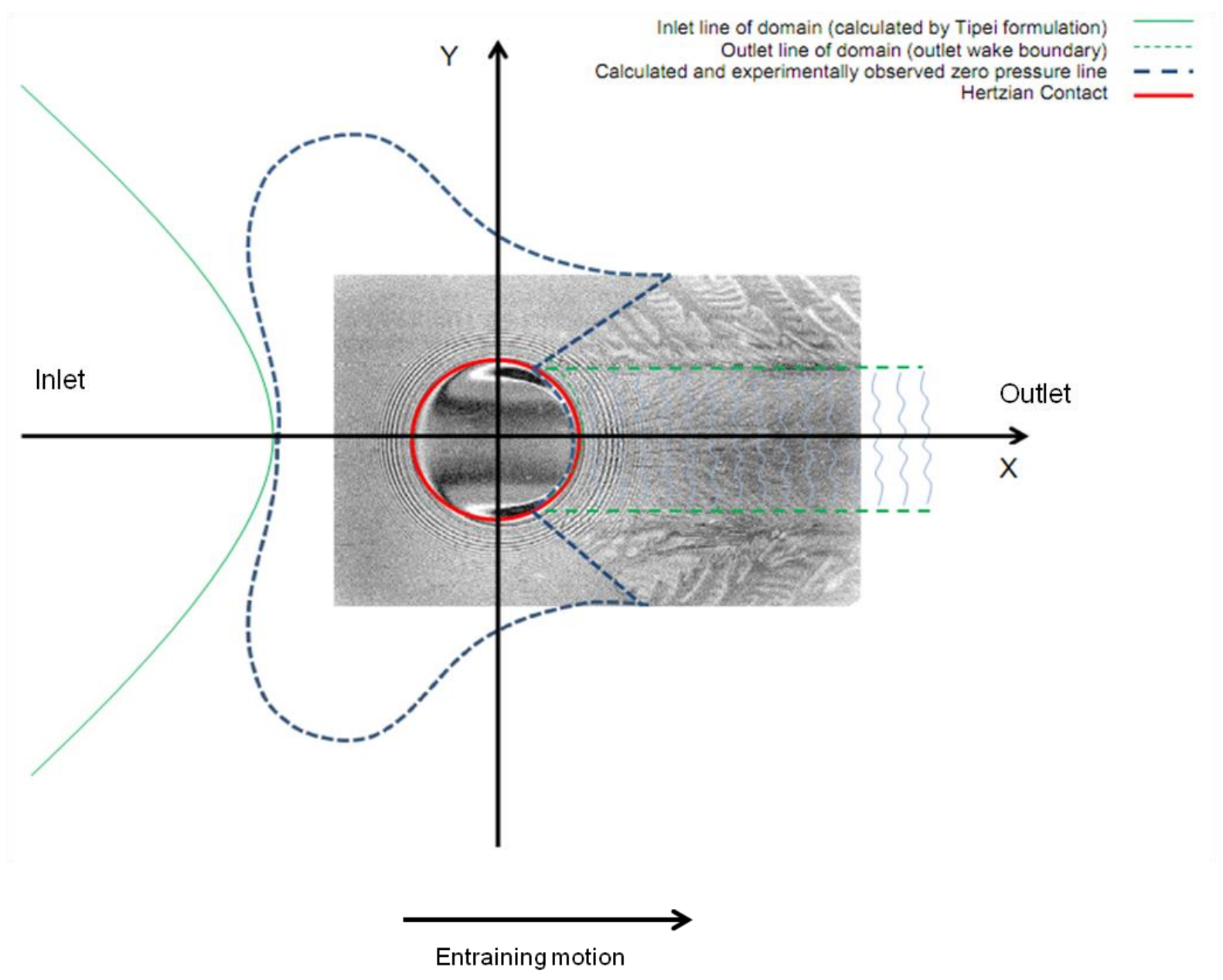

Figure 6: Photo-micrograph of lubricant film interferogram under the same conditions as the isobaric pressure plot of figure 5

\section{Numerical model}

As in all elastohydrodynamic analyses, Reynolds equation forms the basis for the prediction of generated pressures. For the general case of elliptical point contact:

$\frac{\partial}{\partial X}\left[\frac{\bar{\rho} H^{3}}{\bar{\eta}} \frac{\partial P}{\partial X}\right]+\frac{1}{K^{2}} \frac{\partial}{\partial Y}\left[\frac{\bar{\rho} H^{3}}{\bar{\eta}} \frac{\partial P}{\partial Y}\right]=\psi \frac{\partial}{\partial X}[\bar{\rho} H]+K \frac{\partial}{\partial Y}[\bar{\rho} H]$

where: $\Psi=12 \frac{U \eta_{0} R_{z x}^{2}}{P_{\max } b^{3}}$, with $R_{z x}=R_{z y}=R$ and ellipticity ratio, $K=a / b=1$ for circular point contact. Also maximum Hertzian pressure is: $P_{\max }=\frac{3 \mathrm{~W}}{2 \pi R^{2}}$

Equation (10) is used with a usual rectangular computation domain [37, 38]. The contact domain represented by figure 6 is not suitable for numerical analysis. Therefore, co-ordinate transformation is required from the $X Y$ domain in figure 6 to an equivalent rectangular domain $\chi v$, where the transformations are: 


$$
\left\{\begin{array}{c}
\chi(X, Y)=\frac{X-X_{i}(y)}{X_{e}(y)-X_{i}(y)} \\
v(X, Y)=Y
\end{array}\right.
$$

Reynolds equation can now be re-written in terms of this computational domain as:

$$
\begin{aligned}
& \left(b^{2} \chi_{, x}^{2}+K^{2} a^{2} \chi_{, y}^{2}\right) \frac{\partial}{\partial \chi}\left[\frac{\bar{\rho} H^{3}}{\bar{\eta}} \frac{\partial p}{\partial \chi}\right]+K^{2} a^{2} \frac{\partial}{\partial v}\left[\frac{\bar{\rho} H^{3}}{\bar{\eta}} \frac{\partial p}{\partial v}\right]+K^{2} a^{2} \chi, y\left\{\frac{\partial}{\partial \chi}\left[\frac{\bar{\rho} H^{3}}{\bar{\eta}} \frac{\partial p}{\partial \chi}\right]+\frac{\partial}{\partial v}\left[\frac{\bar{\rho} H^{3}}{\bar{\eta}} \frac{\partial p}{\partial v}\right]\right\}= \\
& \Psi\left\{\left(b \chi_{, x}+K a \chi, y\right) \frac{\partial \bar{\rho} H}{\partial \chi}+K a \frac{\partial \bar{\rho} H}{\partial v}\right\}
\end{aligned}
$$

where:

$\chi_{, x}=\frac{\partial \chi}{\partial x}, \chi_{, y}=\frac{\partial \chi}{\partial y}, v_{, x}=\frac{\partial v}{\partial x}, v_{, y}=\frac{\partial v}{\partial y}=1$

The transformation from $\chi, v$ to the $x, y$ domain is obtained from equation (11) for the simultaneous solution of Reynolds equation with the gap shape (elastic film shape) and the lubricant rheological state equations.

The elastic film shape in the $x, y$ domain is given as:

$$
h(x, y)=h_{0}+s(x, y)+\delta(x, y)
$$

where the undeformed profile is: $s(x, y)=\frac{x^{2}}{2 R_{z x}}+\frac{y^{2}}{2 R_{z y}}$, where for a ball contacting a flat race: $R_{z x}=R_{z y}=R$

The local contact deflection is obtained through solution of the elasticity potential equation $[9,38,40]$ :

$$
\delta(x, y)=\frac{1}{E_{r}} \iint_{A} \frac{p\left(x_{1}, y_{1}\right) d x_{1} d y_{1}}{\sqrt{\left(x-x_{1}\right)^{2}+\left(y-y_{1}\right)^{2}}}
$$

Lubricant rheological state; density and viscosity variations with pressure are given by:

For density [3]:

$$
\rho=\rho_{0}\left(1+\frac{0.6 \times 10^{-9} p}{1+1.7 \times 10^{-9} p}\right)
$$

For viscosity [41]: 
$\eta=\eta_{0} \exp \left\{\left[\left(\ln \eta_{0}+9.67\right) \times\left(1+5.1 \times 10^{-9} p\right)^{Z}\right]-\left[\ln \eta_{0}+9.67\right]\right\}$

Where: $Z=\frac{\alpha c_{p}}{\left(\ln \eta_{0}+9.67\right)}=\frac{\alpha}{5.1 \times 10^{-9}\left(\ln \eta_{0}+9.67\right)}$, as $c_{p}=1.96 \mathrm{MPa}$

Note that isothemal conditions are assumed for this analysis.

The solution is obtained using the low relaxation effective influence Newton-Raphson (EIN) method with Gauss-Seidel iterations. The process is fully described in $[10,38]$. This method is widely used in elastohydrodynamic studies. However, more detailed, yet with longer computation times can also be used, such as multi-level, multi-grid technique $[42,9]$. Another approach is through use of finite element analysis for example by Tan et al [43]. Additionally, modified Reynolds equation may be used with boundary conditions suitable for inclusion of cavitaion effect, such as that reported by Elrod [44] or the more extensive and computationally complex JFO boundary conditions $[45,46]$. However, the effect of cavitaion is not taken into account in the current study, because the negative pressure values shown in figure 3(a) have no definitive physical meaning as the micro-transducer readings can only be relied on when in compression. The pressure traces are only used to determine the position of film rupture (i.e. $p=0$ ). Hence, the numerical method used here suffices, although the study of cavitation merits further consideration as this also affects contact friction.

Two convergence criteria are employed in the iteration process; pressure convergence and load balance.

For pressure convergence:

$$
\sum_{i} \sum_{j}\left|\frac{p_{i, j}^{k}-p_{i, j}^{k-1}}{p_{i, j}^{k}}\right| \leq \varepsilon_{p}
$$

where the error tolerance is: $10^{-5} \leq \varepsilon_{p} \leq 10^{-4}$

The subscripts: $i, j \equiv x, y$ denotes the computational discretised domain and the superscript $k$ is the iteration counter for pressure convergence calculations.

If the criterion is not met, then the generated pressures are under-relaxed as:

$$
p_{i . j}^{k}=p_{i, j}^{k-1}+\Omega \Delta p_{i, j} \in i, j
$$


where the under-relaxation factor is typically: $0.01 \leq \Omega \leq 0.8$

For load-balance:

$$
\left|\frac{F-W}{F}\right| \leq \varepsilon_{w}
$$

where the error tolerance is: $0.001 \leq \varepsilon_{w} \leq 0.05$

If the criterion is not met, the initial guess value for the minimum clearance $h_{0}$ is adjusted and the entire iteration process is repeated:

$$
h_{0}^{l}=h_{0}^{l-1}\left(\frac{F}{W}\right)^{\varsigma}
$$

The superscript $/$ is the iteration counter for the whole process; load balance, including the necessary pressure convergence iterations $k$

The damping factor for load balance is given as: $-0.1 \leq \varsigma \leq 0.1$

\section{Numerical Predictions}

Figure 7 shows the predicted isobaric pressure distribution obtained using the computational boundaries indicated in figure 6 . It is comparable with that experimentally measured in figure 4 .

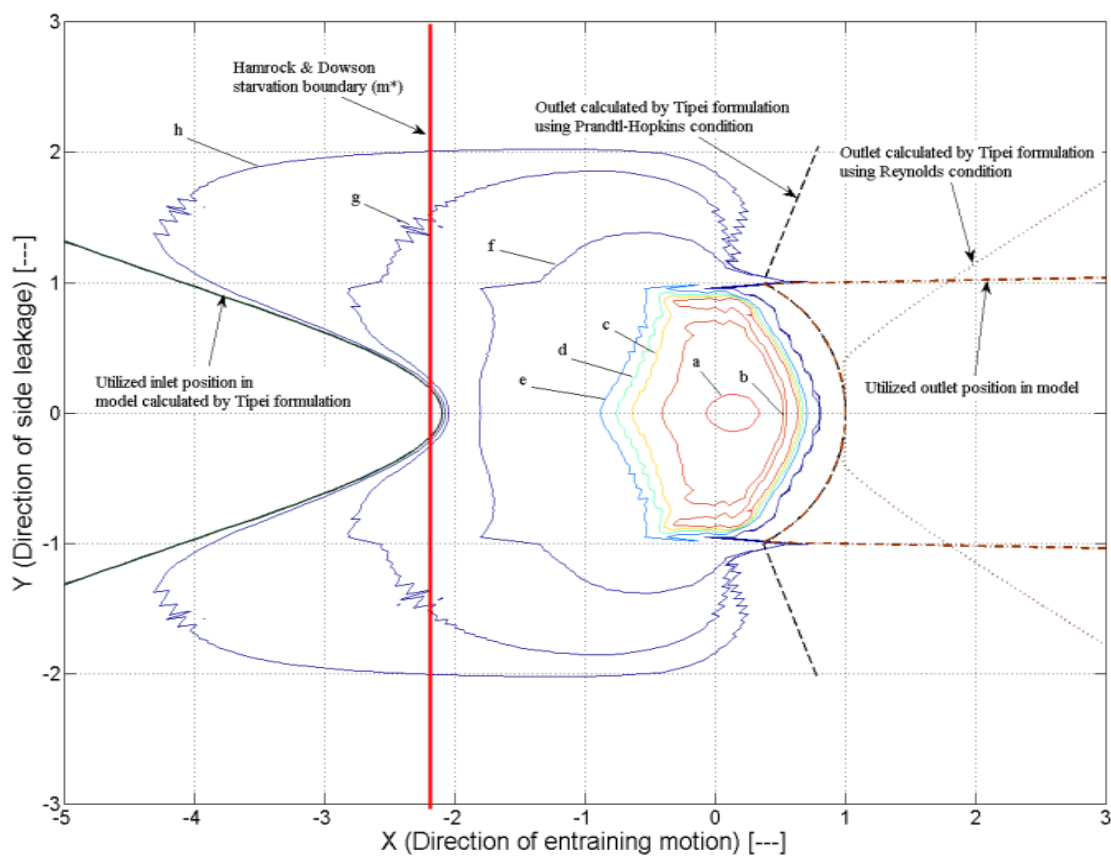


Figure 7: Predicted isobaric pressure distribution for the same conditions as those of measured pressures in figure 4

Key: Pressures in GPa: $a=0.7, b=0.58, c=0.35, d=0.21, e=0.13, f=0.0007, g=0.00005, h=0$

Good agreement can be observed between the predictions and the measured results. There are some differences, most likely caused by the computational mesh density; in this case a grid of $i, j \equiv 120 \times 120$, which already accounts for a significant computation time. There is also a spatial measurement resolution (resolving power of the active element of the miniature transducer), determined by its width of $10 \mu \mathrm{m}$. However, good agreement between the predicted and measured results suffices in noting the importance of using true boundary conditions in numerical predictive simulations. This is demonstrated by the results in figure 8 (a), where the "rectangular domain" refers to the usually assumed fully flooded inlet boundary 4-5 times the Hertzian contact radius ahead of the centre of the contact and an outlet boundary based on the Swift-Stieber boundary conditions. Clearly, a thicker lubricant film is predicted with the usual approach than with the current analysis. The current paper is not primarily concerned with issue of starvation, although this phenomenon results as a repercussion of the use of true boundary conditions. More specific studies of lubricant film thickness under different levels of starvation have been carried out by Qian et al [47] and Damiens et al [48]. There is limitation in applied load due to the use of a toughened glass race. The conditions are elastohydrodynamic, where the lubricant film thickness is insensitive to load, whilst the contact dimensions increase as well as generated pressures.

The central cuts through the pressure distributions in the direction of entraining motion for the measured and predicted pressures are shown in figure 8(b). The results of the current analysis conform better to the measured pressure profile than that based on a fully flooded inlet. 


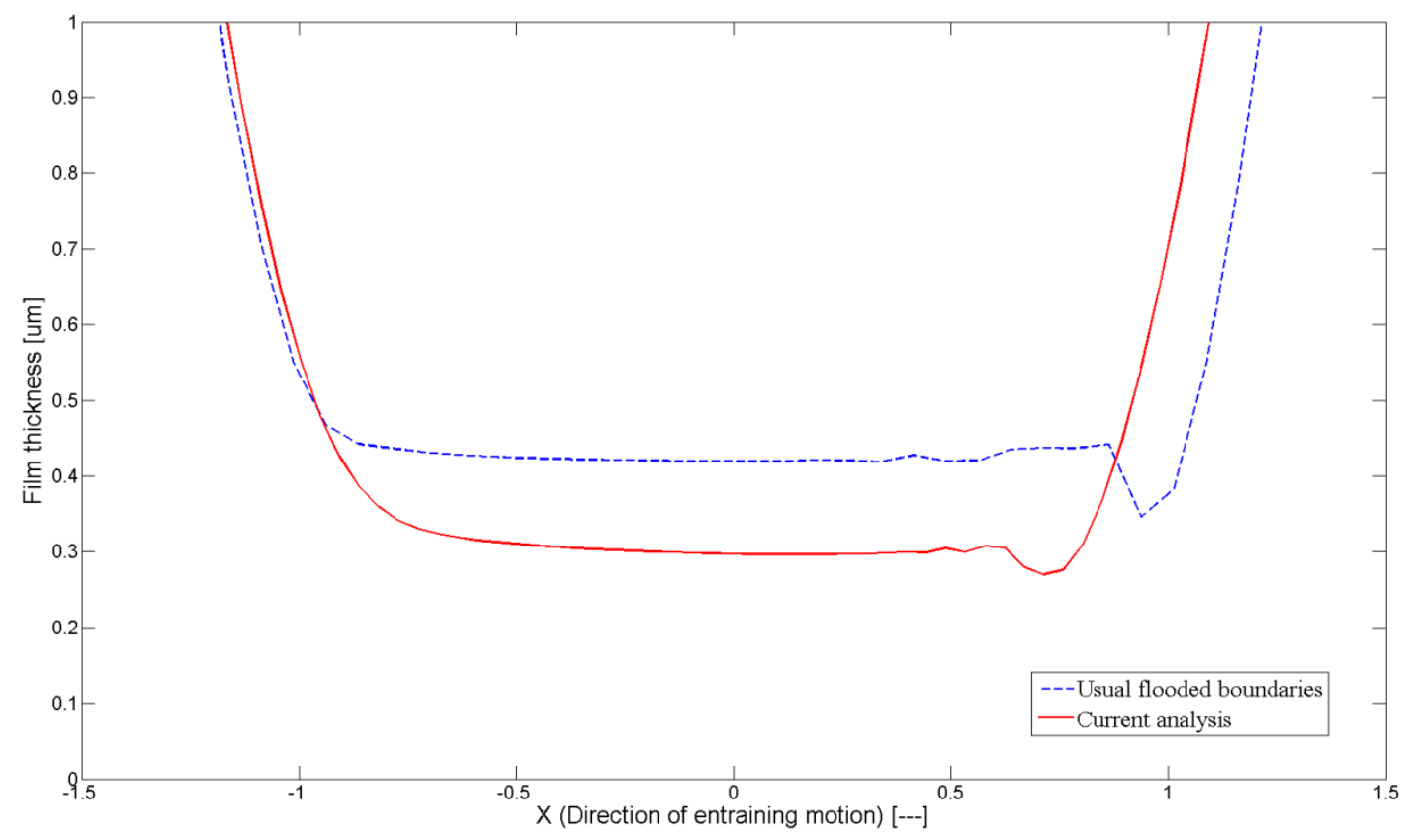

(a)- Film shape

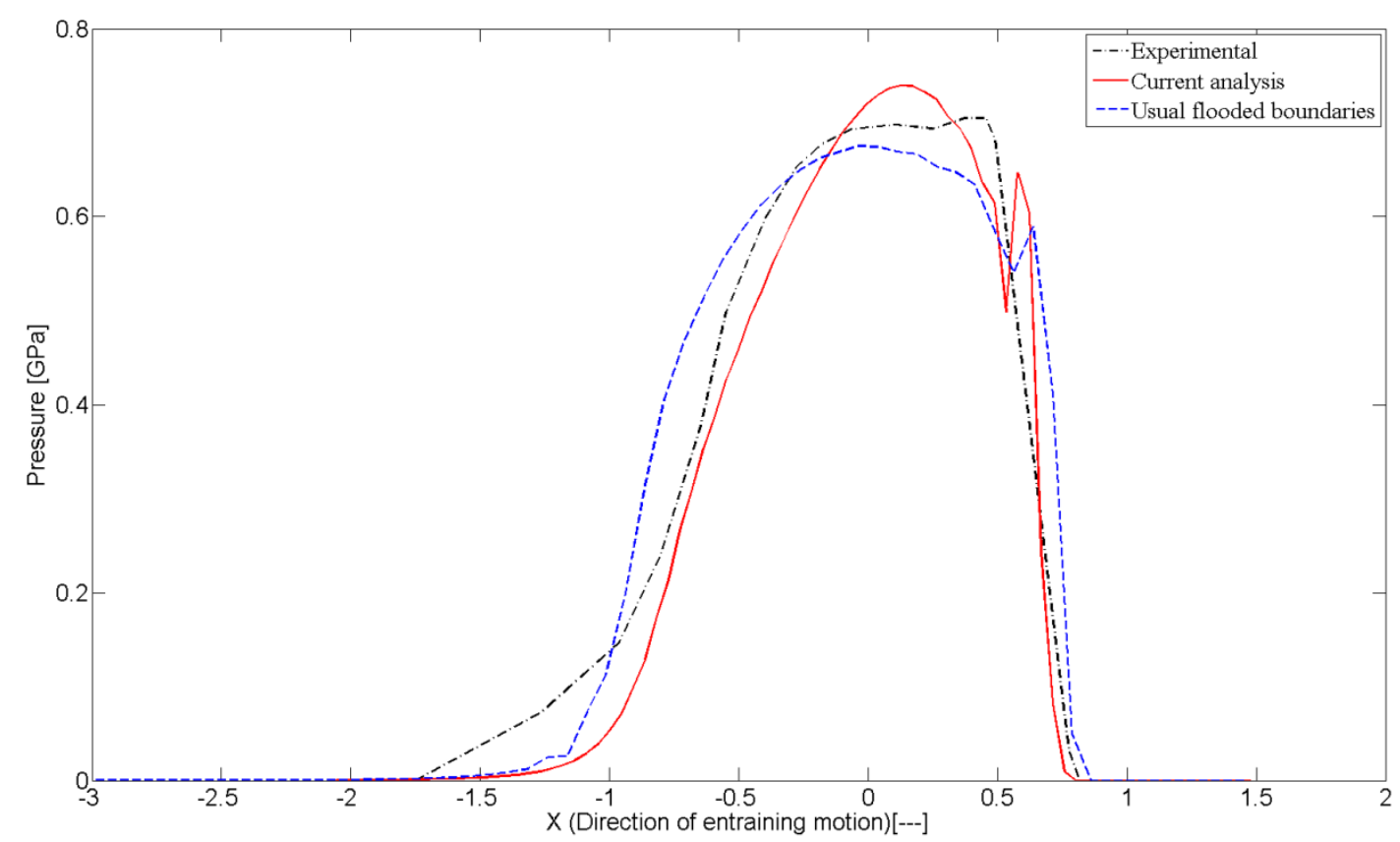

(b)- Pressure profile

Figure 8: Predicted and measured central film shape and pressure profile in the direction of entraining motion 
In both cases the regime of lubrication is surmised to be elastohydrodynamic because the Stribeck oil film parameter is: $\lambda=\frac{h_{0}}{\sigma} \approx 3$, with the composite surface roughness Ra being, $\sigma=\sqrt{0.05^{2}+0.08^{2}} \approx 0.094 \mu \mathrm{m}$ (see section 2). Thus, for the flooded results: $\lambda_{f}=\frac{0.325}{0.094} \approx 3.5$ and for the current analysis: $\lambda_{c}=\frac{0.26}{0.094} \approx 2.8$. Nevertheless, with the reduced film thickness in the case of the current analysis (fore-shortened inlet boundary), there is increased viscous shear of the lubricant at the same speed of entraining motion and lubricant viscosity with the ratio: $\frac{\tau_{c}}{\tau_{f}}=\frac{h_{0 f}}{h_{0 c}} \propto \frac{\lambda_{f}}{\lambda_{c}}=1.25$, where subscripts $c$ and $f$ refer to the current analysis, based on the employed boundary conditions and those for the fully flooded inlet respectively. Note that viscous friction, $\tau \propto \frac{U \eta R}{h_{0}}$ with the assumption of the dominance of Couette shear. Therefore, $25 \%$ more friction would be expected than that under idealised generally assumed fully flooded inlet. This behaviour of friction with starvation has been observed experimentally by Ali et al [49].

\section{Concluding remarks}

The paper has developed inlet and outlet boundary conditions using entrainment flow with partial counter-flow in pure rolling of contiguous surfaces in circular elastohydrodynamic point contact. The results show that the inlet meniscus is partially formed inside the starvation demarcation boundary, found through experimental work of Wedeven et al [33] and numerical analysis by Hamrock and Dowson [32] (figure 7), based on Swift-Stieber exit boundary conditions. Crucially, the inlet distance feeding the central Hertzian region of the contact falls within this starvation boundary. This region often has a flat thin film thickness as well as the minimum exit film shown in figure 8(a). This finding indicates that elastohydrodynamic conjunctions are often starved even under nominally pure rolling conditions, as has often been surmised but not fundamentally determined. This is a repercussion of the application of correct inlet boundary conditions. An important repercussion of these findings is that the usual assumption of flooded inlet and exit boundary conditions renders a thicker lubricant film thickness than that measured through interferometry. This means that a higher viscous friction would be expected in practice than that usually predicted.

The main contribution of this paper is the good conformance of numerical predictions, using the analytically established boundary conditions with the experimentally 
measured pressure distribution, an approach not hitherto reported in literature for the observed key-hole shaped conjunctions.

\section{8- References}

[1] Grubin, A.N., : Contact stresses in toothed gears and worm gears. Central Scientific Research Institute for Technology and Mechanical Engineering 30 (337), (1949)

[2] Ertel, A.M., : Hydrodynamic lubrication based on new principles. Akad. Nauk.,SSSR, Prikadnaya Mathematica i Mekkanika 3 (2), 41-52 (1939)

[3] Dowson, D., Higginson, G.R., : A numerical solution to elastohydrodynamic problem. J. Mech. Engng. Sci. 1 (1), 6-15 (1959)

[4] Archard, J.F., Kirk, M.T., : Lubrication at point contacts. Proc. Roy. Soc., A23, 261 (1307), 532$550(1961)$

[5] Archard, J.F., Cowking, E.W., : EHL lubrication at point contacts. Proc. IMechE, J. Mech. Engng. Sci. 180 (2), 47-56 (1965)

[6] Cameron, A., Gohar, R., : Theoretical and experimental studies of oil film thickness in lubricated point contact. Proc. Roy. Soc., A 26, 291 (1427), 520-536 (1966)

[7] Gohar, R., Cameron, A., : Optical measurement of oil film thickness under elasto-hydrodynamic lubrication. Nature, 200, 458-459 (1963)

[8] Chittenden R. J., Dowson, D., Dunn J. F., Taylor, C. M., : A theoretical analysis of EHL concentrated contacts Parts I and II. Proc Roy. Soc., A 387, 245-269 and pp. 271-295 (1985)

[9] Jalali-Vahid, D., Rahnejat, H., Gohar, R., Jin, Z.M., : Comparison between experiments and numerical solutions for isothermal elastohydrodynamic point contacts. J. Phys., D: Appl. Phys., 31 (20), 2725-2732 (1998)

[10] Jalali-Vahid, D., Rahnejat, H., Gohar, R., Jin, Z.M., :Prediction of oil-film thickness and shape in elliptical point contacts under combined rolling and sliding motion. Proc. IMechE, Part J: J. Engng. Trib., 214, 427-437 (2000)

[11] Thorp, N., Gohar, R., : Oil film thickness and shape for a ball sliding in a grooved raceway. Trans. ASME, J. Lubn. Tech. 94 (3), 199-209 (1972)

[12] Mostofi, A., Gohar, R., : Elastohydrodynamic lubrication of finite line contacts. Trans. ASME, J. Lubn. Tech. 105 (4), 598-604 (1983)

[13] Kushwaha, M., Rahnejat, H., Gohar, R., : Aligned and misaligned contacts of rollers to races in elastohydrodynamic finite line conjunctions. Proc. IMechE, Part C: J. Mech. Eng. Sci. 216, 10511069 (2002)

[14] Johns, P.M., : The Design of Cylindrical Rollers for use in Shaft and Bearing Systems. MSc Thesis, Imperial College of Science and Technology, (1978)

[15] Hartnett M., Kannel, J., : Contact stresses between elastic cylinders - A comprehensive theoretical and experimental approach. Trans. ASME, J. Lubn. Tech. 103 (1), 40-45 (1981) 
[16] Johns, P.M., Gohar, R., : Roller bearings under radial and eccentric loads. Trib. Int., 14 (3), 131$136(1981)$

[17] Wymer, D. G., Cameron, A., : EHL lubrication of a line contact. Part 1: optical analysis of a roller bearing. Proc. IMechE, J. Mech. Engng. Sci. 188 (1), 221-238 (1974)

[18] Foord, C.A., Wedeven, L.D., Westlake, F.J., Cameron, A., : Optical elastohydrodynamics. Proc. IMechE, J. Mech. Engng. Sci. 184 (1), 487-505 (1969)

[19] Bridgeman, P.W., : The physics of high pressure, V.G. Bell \& Sons, London, 330 (1949)

[20] Kannel, J.W., Bell, J.C., Allen, C.M., : Methods for Determining Pressure Distributions in Lubricated Rolling Contact. Trans. ASLE, Trib. Trans. 8 (3), 250-270 (1965)

[21] Kannel, J.W., : Comparison Between Predicted and Measured Axial Pressure Distribution Between Cylinders. Trans. ASME, J. Lubn. Tech. 96 (3), 508-515 (1974)

[22] Hamilton, G.M., Moore, S.L., : Deformation and pressure in an elastohydrodynamic contact. Proc. Roy. Soc., London, Series A-322, 322 (1550), 313-330 (1967)

[23] Bartz, W.J., Ehlert, J., : Influence of pressure viscosity of lubrication oils on pressure, temperature and film thickness in elastohydrodynamic rolling contacts. Trans. ASME, J. Trib. 98 (4), 500-507 (1976)

[24] Safa, M.M.A., Leather, J.A., Anderson, J.C., : Thin film microtransducers for elastohydrodynamic studies. Thin Film Solids, 64 (2), 257-262 (1979)

[25] Johns-Rahnejat, P.M., Gohar, R., : Point contact elastohydrodynamic pressure distribution and sub-surface stress field. Tri-Annual Conf. on Multi-body Dynamics, Monitoring \& Simulation Techniques, 161-177 (1997)

[26] Teodorescu, M., Kushwaha, M., Rahnejat, H., Rothberg, S.J., : Multi-physics analysis of valve train systems: from system level to microscale interactions. Proc. Instn. Mech. Engrs., Part K: J. Multi-body Dyn. 221 (3), 349-361 (2007)

[27] Al-Samieh, M.F., Rahnejat, H., : Physics of lubricated impact of a sphere on a plate in a narrow continuum to gaps of molecular dimensions. J. Phys., D: Appl. Phys. 35 (18), 2311-2326 (2002)

[28] Safa, M.M.A., Gohar, R., : Pressure distribution under a ball impacting a thin lubricant layer. Trans. ASME, J. Trib., 108 (3), 372-376 (1986)

[29] Johns-Rahnejat, P.M., : Pressure and stress distributions under elastohydrodynamic point contacts. PhD Thesis, Imperial College of Science, Technology and Medicine, (1988)

[30] Johns-Rahnejat, P.M., Gohar, R., : Measuring contact pressure distributions under elastohydrodynamic point contacts. Tribotest, 1 (1), 33-53 (1994)

[31] Tipei, N., : Boundary Conditions of a Viscous Flow Between Surfaces With Rolling and Sliding Motion. Trans. ASME, J. Lubn. Tech. 90 (1), 8-16 (1968) 
[32] Hamrock, B.J., Dowson, D., : Isothermal elastohydrodynamic lubrication of point contacts, Part IV - Starvation results. Trans. ASME, J. Lubn. Tech. 99, 15-23 (1977)

[33] Wedeven, L.D., Evans, D., Cameron, A., : Optical analysis of ball bearing starvation. Trans. ASME, J. Lubn. Tech. 93, 349-363 (1971)

[34] Safa, M. M. A., Anderson, J. C., Leather, J. A., : Transducers for pressure, temperature and oil film thickness measurement in bearings. Sensors and Actuators 3, 119-128 (1983)

[35] Wisniewski, R., Molinar, G. F., : Friction free active-element bulk-modulus high-pressure transducer. Review of scientific instruments, 67 (5), 2020-2021 (1996)

[36] Pemberton, J., Cameron, A., : A mechanism of fluid replenishment in elastohydrodynamic contacts. Wear, 37 (1), 185-190 (1976)

[37] Hamrock, B.J., Dowson, D., : Isothermal elastohydrodynamic lubrication of point contacts, Part I - Theoretical formulation. Trans. ASME, J. Lubn. Tech. 98, 223-229 (1976)

[38] Jalali-Vahid, D., Rahnejat, H., Jin, Z.M., Dowson, D., : Transient analysis of isothermal elastohydrodynamic circular point contacts. Proc. Instn. Mech. Engrs., J. Mech. Engng. Sci., 215, 1159-1172 (2001)

[39] Birkhoff, G., Hays, D., : Free Boundaries in Partial Lubrication: J. Math. and Phys., 42 (2), 126$138(1963)$

[40] Gohar, R., Rahnejat, H., : Fundamentals of Tribology. Imperial College Press, London, (2008)

[41] Roelands C. J. A., : Correlation aspects of the viscosity-temperature-Pressure relationships of lubricating oils. Druk VRB Kleine der A3-4 Groningen, (1966)

[42] Venner, C.H., Lubrecht, A.A., : Multigrid techniques: a fast and efficient method for the numerical simulation of elastohydrodynamically lubricated point contact problems. Proc. Instn. Mech. Engrs., J. Engng. Trib. 214, 42-63 (2000)

[43] TAN, Xincai, et al. : Computational approaches for modelling elastohydrodynamic lubrication using multiphysics software. Proceedings of the Institution of Mechanical Engineers, Part J: Journal of Engineering Tribology, 226 (6), 463-480 (2012)

[44] Elrod, H. G., : A cavitation algorithm. Trans. ASME, J. lubn. Tech. 103 (3), 350-354 (1981) 
[45] Jakobsson, B., Floberg, L., : The finite journal bearing considering vaporisation. Trans. Of Chalmers University of Technology, 103, (1957)

[46] Olsson, K. O., : Cavitation in dynamically loaded bearings. Trans. of Chalmers University of Technology, 26, (1965)

[47] Qian, S., et al. : Experimental Investigation of Lubricant Flow Properties Under Micro Oil Supply Condition. Journal of Tribology, 134, (2012)

[48] Damiens, B., Venner, C.H., Cann, P.M.E., Lubrecht, A.A., : Starved lubrication of elliptical EHD contacts. Journal of tribology, 126 (1), 105-111 (2004)

[49] Ali, F., Krupka, I., Hartl, M., : Analytical and experimental investigation on friction of non-conformal point contacts under starved lubrication. Meccanica, 48 (3), 545-553 (2013) 